\title{
ANALISIS KESEHATAN REPRODUKSI PADA REMAJA
}

\author{
Sri Emilda \\ Program Studi D III Kebidanan STIKES Mitra Adiguna Palembang \\ Komplek Kenten Permai Blok J No. 9-12 Bukit Sangkal Palembang 30114 \\ Email : sriemilda1@gmail.com
}

\begin{abstract}
Abstrak
Remaja cenderung ingin selalu mencoba mencari tahu. Remaja enggan untuk bertanya kepada orang tua karena sebagian besar keluarga di Indonesia menganggap tabu untuk membicarakan masalah seksualitas dengan anak yang belum menikah. Perkembangan kasus HIV/AIDS di Indonesia masih menjadi persoalan dan menunjukkan peningkatan dari tahun ke tahun dengan jumlah tertinggi ada pada provinsi Papua, Jawa Timur dan DKI Jakarta. Secara kumulatif penderita AIDS dari tahun 1987 sampai dengan Desember 2016 adalah sebanyak 86.780 orang. Oleh karena itu, pendidikan seksual penting diberikan sejak usia dini. Tujuan penelitian ini untuk mengetahui analisis kesehatan reproduksi pada remaja. Fokus penelitian ini pada penelitian kualitatif dengan desain penelitian survei deskriptif. Penelitian melibatkan 2 remaja, 2 ibu orang tua remaja dan 1 dokter kandungan sebagai partisipan. Hasil penelitian bahwa kedua remaja partisipan penelitian masih belum maksimal menjaga kesehatan reproduksi karena kurangnya pemahaman dari remaja dan pihak keluarga mengenai cara menjaga kesehatan reproduksi. Kesimpulan kedua remaja partisipan belum maksimal menjaga dan merawat kesehatan reproduksinya, kedua remaja partisipan mengetahui mengenai dampak kehamilan remaja, bahaya rokok, miras dan narkoba, dan mengetahui yang dimaksud dengan PMS dan kekerasan seksual. Saran diharapkan para remaja dapat memahami dengan benar tentang cara menjaga dan merawat kesehatan reproduksi dan dapat menghindari perilaku seksual yang berbahaya dengan menggali informasi dari berbagai sumber.
\end{abstract}

\section{Kata Kunci: Kesehatan Reproduksi, Remaja, Seksual}

Bahan Bacaan : 12 (2012-2018)

\begin{abstract}
Teenagers tend to want to always try to find out. Teenagers are reluctant to ask parents because most families in Indonesia consider it taboo to discuss sexuality issues with unmarried children. The development of HIV / AIDS cases in Indonesia is still a problem and shows an increase from year to year with the highest number in the provinces of Papua, East Java and DKI Jakarta. Cumulatively, AIDS sufferers from 1987 to December 2016 were 86,780 people. Therefore, it is important to provide sexual education from an early age. The purpose of this study was to determine the Analysis of Adolescents on Reproductive Health. The focus of this study was on qualitative research using descriptive survey research methods, aimed at adolescents. Descriptive research design. The study involved 2 teenagers, 2 mothers and 1 obstetrician as participants. The results of the study illustrate adolescent knowledge about reproductive health is quite good. The results showed that the two adolescent participants in the study had not been maximally maintaining reproductive health due to a lack of understanding from the teenagers and their families about how to maintain reproductive health. The conclusion of the two adolescent participants had not been maximally maintaining and caring for their reproductive health, the two young participants knew about the impact of teen pregnancy, the dangers of smoking, alcohol and drugs, and knew what STDs and sexual violence meant. Suggestions are expected that adolescents can understand correctly about how to maintain and care for reproductive health and can avoid dangerous sexual behavior by gathering information from various sources.
\end{abstract}

Keywords: Reproductive Health, Adolescents, Sexual

Reading Material: 12 (2012-2018)

Jurnal Kesehatan dan Pembangunan, Vol. 11, No. 21, Januari 2021 


\section{PENDAHULUAN}

Kesehatan reproduksi adalah merupakan hal yang sangat penting baik individu maupun masyarakat karena berpengaruh dalam siklus kehidupan dan keberlangsungan kehidupan manusia. Cairo, ICPD Program of Action menyebutkan bahwa kesehatan reproduksi adalah merupakan keadaan sejahtera fisik, mental dan sosial secara utuh, yang tidak sematamata bebas dari penyakit atau kecacatan, dalam semua hal yang berkaitan dengan sistem reproduksi, serta fungsi dan prosesnya (Noviana, 2018).

Pada masa pubertas, seseorang mulai beranjak remaja sehingga ada banyak perubahan yang terjadi di dalam tubuhnya baik dari segi fisik maupun psikologinya. Remaja adalah suatu masa dimana individu berkembang dari saat pertama kali ia menunjukkan tanda-tanda seksual sekundernya sampai saat ia mencapai kematangan seksual (Sarwono, 2011). Masa remaja disebut juga sebagai masa perubahan, meliputi perubahan dalam sikap, dan perubahan fisik (Pratiwi, 2012).

Remaja cenderung ingin selalu mencoba mencari tahu. Remaja enggan untuk bertanya kepada orang tua karena sebagian besar keluarga di Indonesia menganggap tabu untuk membicarakan masalah seksualitas dengan anak yang belum menikah. Karena alasan inilah, remaja seringkali mencari informasi melalui teman sebaya ataupun lingkungannya yang belum tentu memiliki pengetahuan yang benar tentang kesehatan reproduksi remaja (Dhafir, 2014).

Oleh karena itu, pendidikan seksual penting diberikan sejak usia dini. Anak perempuan secara khusus, perlu diberikan pengetahuan dan pemahaman yang benar tentang pendidikan seksual sehingga dirinya memiliki kesadaran tentang besarnya konsekuensi dan tanggung jawab yang dihadapi apabila mereka tidak berhati-hati saat memasuki masa atau periode aktif secara seksual. Pengetahuan adalah hasil penginderaan manusia, atau hasil tahu seseorang terhadap suatu objek dari indra yang dimilikinya (Notoatmodjo, 2012).

Hasil survei penduduk antar sensus 2015 menunjukkan bahwa penduduk usia 1524 athun mencapai 42.061,2 juta atau sebesar $16,5 \%$ dari total penduduk Indonesia. Hasil proyeksi penduduk menunjukkan bahwa jumlah penduduk menunjukkan bahwa jumlah penduduk usia remaja ini akan mengalami peningkatan hingga tahun 2030 dan akan menurun sesudahnya. Perubahan jumlah penduduk usia remaja tersebut terkait dengan transisi demografi di Indonesia, struktur usia penduduk. Awalnya, proporsinya terbesar adalah penduduk muda (usia 0-14 tahun) dengan menurunnya fertilitas, terjadi perubahan dimana proporsi penduduk yang dominan bukan lagi penduduk muda tetapi penduduk usia produktif (15-64). Di antara mereka yang ada dalam kelompok usia produktif tersebut adalah remaja usia 15-24 tahun. Mereka inilah yang kelak akan menjadi kelompok penduduk dewasa dan tua pada tahun 2030 (Briefs Notes Lembaga Demografi FEB UI Juni 2017).

Berdasarkan Survei Demografi dan Kesehatan Indonesia (SKDI) 2012, sebanyak $1,6 \%$ remaja perempuan (110 orang) usia 1519 tahun telah melakukan hubungan seks sebelum berusia 15 tahun. Hanya 40,5\% (2.805 orang) remaja perempuan usia 15-19 tahun yang menggunakan kondom ketika berhubungan seksual dan hanya $61 \%$ (4.225 orang) yang membatasi hubungan dengan satu pasangan. Hubungan seksual yang dilakukan pada usia yang sangat muda meningkatkan kemungkinan seseorang terinfeksi HIV, terutama jika melibatkan pasangan seksual yang beresiko atau pasangan yang berganti-ganti dan penggunaan kondom yang rendah. Selain resiko HIV, melakukan hubungan seksual yang terlalu dini pada remaja juga berdampak pada aborsi yang tidak aman, pernikahan dini, dan melahirkan di usia yang masih sangat muda (SDKI, 2012).

Perkembangan kasus HIV/AIDS di Indonesia masih menjadi persoalan dan 
menunjukkan peningkatan dari tahun ke tahun dengan jumlah tertinggi ada pada provinsi Papua, Jawa Timur dan DKI Jakarta. Secara kumulatif penderita AIDS dari tahun 1987 sampai dengan Desember 2016 adalah sebanyak 86.780 orang. Persentase kumulatif AIDS tertinggi pada kelompok usia 20-29 tahun $(31,4 \%)$. Sementara itu, untuk usia 1519 tahun adalah sebesar 2,7 persen (Ditjen PP \& PL, Kementerian Kesehatan RI, 2016) (Briefs Notes Lembaga Demografi FEB UI Juni 2017).

Remaja laki-laki usia 15-19 tahun memiliki prosentase lebih tinggi dalam seks pra-nikah dibandingkan remaja perempuan. Sekitar $4,5 \%$ remaja laki-laki dan $0,7 \%$ remaja perempuan pernah melakukan seks pra-nikah. Alasan melakukan hubungan seksual yang paling banyak diungkapkan adalah, 57,7\% remaja laki-laki karena penasaran/rasa ingin tahu, $38 \%$ remaja perempuan menyatakan terjadi begitu saja, dan $12,6 \%$ remaja perempuan menyatakan melakukan hubungan seksual karena dipaksa oleh pasangan mereka. Kesadaran yang rendah terkait isu kesehatan dan seksualitas, tekanan sosial dari lingkungan pertemanan, dan pola hubungan yang tidak seimbang menjadi sumber permasalahan kesehatan remaja (SDKI, 2012).

\section{METODE PENELITIAN}

\section{Jenis Penelitian}

Penelitian ini menggunakan
pendekatan deskriptif kualitatif.

\section{Waktu dan Tempat Penelitian}

Penelitian ini dilaksanakan pada bulan April - Juni 2020 dan bertempat di rumah partisipan dan klinik dokter.

\section{Target/Subjek Penelitian}

Target/subjek penelitian adalah 2 remaja, 2 ibu orang tua remaja dan 1 dokter kandungan sebagai partisipan.
Teknik memperoleh subjek penelitian dengan observasi dan wawancara partisipan.

Data, Intrumen, dan Teknik

\section{Pengumpulan Data}

Penelitian ini menggunakan data primer yang diperoleh melalui partisipan remaja dengan cara mewawancarai remaja dan orang tuanyasecara mendalam untuk mendapatkan informasi maupun keteranganketerangan yang berkaitan dengan kesehatan reproduksi. Data primer lain juga didapatkan dari informan kunci dokter kandungan untuk mendapatkan informasi yang benar untuk menjelaskan masalah tersebut di atas. Selain itu, penelitian ini juga mempergunakan data sekunder yang diperoleh dari buku-buku, jurnal dan study kepustakaan lainnya.

\section{Teknik Analisis Data}

Dalam penelitian ini dilakukan analisis sebagai berikut:

\section{Reduksi data}

Mereduksi data adalah melakukan pembersihan atau pengurangan data-data yang sudah dikumpulkan yang tidak berkaitan dengan analisis data yang sesuai dengan judul penelitian.

\section{Penyajian data}

Penyajian data dalam penelitian ini dilakukan dengan cara membuat tabulasi atau pelaporan data-data yang diperoleh seperti hasil wawancara secara mendalam dengan partisipan dan hasil wawancara dengan dokter kebidanan.

\section{Menarik kesimpulan}

Setelah itu akan dilakukan penarikan kesimpulan sementara terhadap hasil wawancara yang dilakukan dan mengelompokkannya menjadi satu pada pertanyaan yang sama dan jawaban yang sama atau mirip atau setara.

\section{Verifikasi data}

Verifikasi data dalam penelitian ini dilakukan dengan cara mengecek kembali 
semua daftar pertanyaan yang disesuaikan dengan jawaban pada pertanyaan tersebut selain itu mencari kecocokan antara jawaban baik dari partisipan, bidan dengan teori-teori yang mendukungnya.

\section{HASIL PENELITIAN DAN PEMBAHASAN}

\section{Hasil Penelitian}

Hasil penelitian ini berpedoman pada penelitian studi kasus pada kebidanan bersifat kualitatif, pengumpulan data berupa observasi dibantu alat perekam gambar (video) dan wawancara dibantu dengan pedoman wawancara mendalam, dimana kasus yang diteliti adalah Analisis Kesehatan Reproduksi pada Remaja. Walaupun kasus ini adalah unit tunggal tetapi dalam melakukan analisis mendalam peneliti tidak hanya meneliti partisipan saja sebagai partisipan utama, tetapi juga melibatkan dokter spesialis kandungan sebagai informan kunci dan pendapat peneliti sendiri berdasarkan hasil observasi yang dilakukan dengan bantuan alat rekam untuk memudahkan peneliti dalam mengingat kasus yang terjadi.

\section{Gambaran Partisipan}

Penelitian melibatkan 2 remaja, 2 ibu dan 1 dokter kandungan . Ada pun gambaran umum dari partisipan dalam penelitian ini Siswi "I" berusia 16 tahun dan Siswa "H" berusia 17 tahun, keduanya adalah siswa SMA.Ny "H" berusia 44 tahun dan Ny "D" berusia 48 tahun berpendidikan SMA dan merupakan ibu rumah tangga. Informan kunci dalam penelitian ini adalah seorang dokter spesialis kandungan, berumur 58 tahun, berpendidikan S2 Dokter Spesialis kandungan dan masa kerja sudah lebih dari 20 tahun.

\section{Hasil Observasi}

Observasi Siswa " $H$ " hari Minggu, tanggal 14 Mei 2020, Pukul 10.00 WIB. Di dapatkan informasi Siswa "H" berusia 17 tahun dan beralamat di Jl. Mangkubumi Lr.
Jadi. Siswa "H" merupakan siswa kelas 12 di SMA PUSRI Palembang. Siswa "H" memiliki fisik yang sehat dan bersih. Tetapi di dapatkan juga bahwa Siswa " $\mathrm{H}$ " merupakan perokok aktif.

Observasi Siswi "I" hari Senin, Tanggal 15 Mei 2020, Pukul 13.00 WIB. Di dapatkan informasi Siswi "I" berusia 16 tahun dan beralamat di Jl. Ratu Sianum Lr. Langgar. Siswi "I" merupakan siswi kelas 11 di SMAN 5 Palembang. Siswi "I" memiliki fisik yang sehat. Siswi "I" merupakan remaja yang kurang memperhatikan kebersihan tubuh ataupun sekitarnya.

\section{Pembahasan}

Kedua partisipan menjawab menyadari telah mengalami perkembangan baik fisik, mental ataupun jiwa. Siswa " $\mathrm{H}$ " mengatakan perkembangan yang di alaminya seperti tumbuh jakun, mimpi basah dan suara berubah. Ny "D" mengatakan dilihat dari fisik perkembangan yang di alami anaknya adalah bertambah tinggi, adanya perubahan suara dan tumbuhnya jakun. Ny " $D$ " mengatakan tidak ada yang berubah dari perkembangan kejiwaan/emosi anaknya. Ny "D" mengatakan anaknya mengalami perkembangan sejak usia 15 tahun.

Siswi "I" mengatakan perkembangan yang dialami seperti badan bertambah tinggi, payudara dan bokong membesar. Ny " $\mathrm{H}$ " mengatakan dilihat dari fisik perkembangan yang di alami anaknya adalah bertambah tinggi dan berat badan bertambah. Ny "H" mengatakan perkembangan kejiwaan/emosi anaknya sangat sensitif. Ny " $\mathrm{H}$ " mengatakan anaknya mengalami menstruasi pertama kali (menarche) saat usia 14 tahun, anak Ny " $\mathrm{H}$ " selalu mengeluhkan sakit saat mentruasi dan diberikan terapi obat. Ny " $\mathrm{H}$ " mengatakan sudah membawa anaknya ke dokter dan diberikan obat.

Dr."M" mengatakan dilihat dari faktor obstetrik ginekologi perkembangan fisik wanita indonesia itu baik, akan tetapi bila dilihat akhir-akhir ini karena pergaulan bebas bisa mempengaruhi perkembangan fisiknya. Faktor lingkungan, media, dapat 
mempengaruhi perkembangan fisik dan juga perkembangan mental dari kesehatan reproduksi. Akan tetapi pernyatan patisipan sesuai dengan pernyataan Bakar, S.A (2014), Perubahan fisik dan mental yang terjadi di masa remaja, meliputi :

1. Perubahan fisik masa remaja.

Perubahan fisik remaja, ditandai dengan munculnya tanda-tanda seks primer dan sekunder, yaitu:

a. Tanda-tanda seks primer : terjadinya haid pada remaja putri (menarche); dan mimpi basah pada remaja laki-laki.

b. Tanda-tanda seks sekunder : pada remaja laki-laki terjadi perubahan suara, tumbuhnya jakun, penis dan buah zakar bertambah besar, terjadinya ereksi dan ejakulasi, dada lebih besar, badan berotot, tumbuhnya kumis, cambang dan rambut di sekitar kemaluan dan ketiak; pada remaja putri : pinggul melebar, pertumbuhan rahim dan vagina, payudara membesar, tumbuhnya rambut diketiak dan sekitar kemaluan.

2. Perubahan kejiwaan masa remaja.

Perubahan kejiwaan remaja, meliputi :

a. Perubahan emosi, sehingga remaja menjadi:

- Sensitif (mudah menangis, cemas, frustasi dan tertawa).

- Agresif dan mudah bereaksi terhadap rangsangan luar yang berpengaruh, sehingga misalnya mudah berkelahi.

b. Perkembangan intelegensia, sehingga remaja menjadi:

1). Mampu berpikir abstrak, senang memberikan kritik.

2). ingin mengetahui hal-hal baru, sehingga muncul perilaku ingin mencoba-coba.

c. Perilaku ingin mencoba-coba.

Siswi "I" mengatakan dalam merawat kesehatan reproduksinya dengan cara mengganti celana dalam saat lembab dan membersihkan alat kelaminnya saat mandi menggunakan sabun dan dengan cara mengkonsumsi makanan yang bergizi. Ny " $\mathrm{H}$ " mengatakan mengajarkan anaknya cara merawat kesehatan reproduksi dengan cara mandi bersih-bersih dan rajin mengganti pembalut saat menstruasi.

Siswa "H" mengatakan dalam merawat kesehatan reproduksinya dengan cara mandi bersih-bersih dan dari segi nutrisi dengan cara mengkonsumsi makanan yang sehat. Ny "D" mengatakan tidak pernah mengajarkan anaknya cara merawat kesehatan reproduksinya. Berbeda dengan pendapat Dr."M" yang mengatakan menurut pandangan kesehatan reproduksi cara memelihara kesehatan reproduksi adalah dengan mengikuti saja dari perkembangan hormonalnya. Apa yang dilakukan Siswi "I" dan Siswa "H" belum sepenuhnya sesuai menurut Dokter Sehat (2019), cara menjaga kesehatan reproduksi ada 8 cara yaitu :

1. Menjaga kebersihan reproduksi

Menjaga kesehatan reproduksi merupakan salah satu cara menjaga kesehatan organ reproduksi paling dasar. Seperti yang kita ketahui secara umum memang kebersihan sangat terkait dengan kesehatan. Beberapa cara yang dapat dilakukan untuk menjaga kebersihan organ reproduksi adalah seperti berikut ini:

a. Menjaga organ reproduksi agar tidak lembap. Pastikan untuk mengeringkan area kelamin menggunakan handuk yang lembut, kering dan bersih setiap diperlukan.

b. Rutin mengganti pakaian dalam paling tidak 2 kali sehari.

c. Menggunakan pakaian dalam yang nyaman dan menyerap keringat.

d. Perempuan disarankan untuk membersihkan alat kelamin dari depan ke belakang untuk mencegah kuman di anus masuk ke organ reproduksi.

e. Laki-laki disarankan untuk khitan atau sunat untuk menurunkan risiko penularan penyakit menular seksual. 
2. Menghindari aktivitas seksual yang berisiko

Pemahaman tentang aktivitas seksual yang berisiko adalah hal yang penting. Aktivitas seksual berisiko memiliki beragam bentuk mulai dari hubungan seksual tanpa kontrasepsi hingga berganti-ganti pasangan. Kedua aktivitas ini sama-sama memiliki risiko tinggi menularkan penyakit seksual.

Maka dari itu, mengenalkan risiko penyakit seperti HIV/AIDS dan penyakit menular seksual lainnya pada remaja perlu dilakukan. Jika telah memahami risiko dari aktivitas dan risiko dari berbagai penyakit organ seksual, tentunya seseorang akan lebih sadar akan pentingnya aktivitas seksual yang aman.

3. Menjaga berat tubuh ideal Menjaga berat badan ideal merupakan salah satu cara menjaga kesehatan organ reproduksi. Berat badan ideal dapat diukur menggunakan kalkulator BMI. Berat badan ideal adalah berat badan seseorang proporsional, tidak kurang dan tidak berlebihan. Kelebihan dan kekurangan berat badan memang sering dikaitkan dengan masalah kesehatan, termasuk juga masalah kesuburan dan kesehatan sistem reproduksi. Berat badan ideal dapat menjaga keseimbangan hormon dalam tubuh.

4. Asupan makanan gizi seimbang. Cara menjaga kesehatan organ reproduksi selanjutnya adalah dengan menjaga asupan makanan. Makanan yang paling baik untuk kesehatan adalah makanan dengan gizi seimbang yaitu dengan memenuhi nutrisi sesuai dengan takarannya.

5. Hindari rokok dan alkohol. Rokok dan minuman beralkohol adalah dua hal yang sebaiknya dihindari oleh pria maupun wanita. Keduanya dapat memicu berbagai macam masalah kesehatan, termasuk kesehatan reproduksi. Kebiasan merokok dan minum alkohol pada wanita dikaitkan dengan gangguan ovulasi. Sedangkan pada pria, rokok dan alkohol dianggap dapat memengaruhi kualitas sperma.

6. Istirahat cukup. Istirahat cukup adalah salah satu kunci dari hidup sehat. Cara ini juga merupakan salah satu cara untuk menjaga kesehatan organ reproduksi. Kurangnya istirahat dapat menyebabkan ketidakseimbangan hormon yang berpengaruh pada kesuburan.

7. Perhatikan produk yang digunakan. Menggunakan produk untuk area organ intim tidak bisa dilakukan sembarangan, karena area ini merupakan area yang cukup sensitif. Wanita dihimbau untuk tidak menggunakan produk pembersih organ kewanitaan secara rutin. Produk pembersih tersebut ditakutkan akan membunuh semua bakteri baik pada area kewanitaan. Padahal bakteri ini sangat penting untuk menjaga $\mathrm{pH}$ area tersebut. Jika bakteri baik juga hilang, risiko infeksi justru akan lebih tinggi.

8. Memeriksakan diri secara rutin. Memeriksakan kesehatan organ reproduksi tidak harus menunggu munculnya gejala penyakit. Sering kali suatu penyakit tidak menunjukkan gejala yang dapat kita sadari. Jika penyakit baru terdeteksi ketika sudah parah, tentu akan lebih sulit untuk mengatasinya. Pemeriksaan rutin adalah langkah untuk memastikan organ reproduksi Anda sehat dan untuk deteksi dini penyakit agar penanganannya dapat lebih cepat. Pemeriksaan ini harus dilakukan secara rutin baik bagi pria maupun wanita. Pada dasarnya cara menjaga kesehatan organ reproduksi tidak jauh berbeda dengan cara menjaga kesehatan secara umum. Agar organ reproduksi tetap sehat, Anda sebaiknya menerapkan pola hidup sehat secara keseluruhan.

Siswi "I" mengatakan dampak yang ditimbulkan dari kehamilan remaja diantaranya adalah malu pada lingkungan, putus sekolah dan fisiknya yang masih lemah. Ny "H" mengatakan remaja bisa mengalami keguguran dikarenakan rahim 
yang belum kuat dan remaja yang masih labil. Ny " $H$ " mengatakan anaknya tidak diperbolehkan pacaran dan memakai hijab untuk meminimalkan kemungkinan orang berbuat jahat.

Siswa"H" mengatakan dampak dari kehamilan remaja seperti membuat malu keluarga dan merusak masa depan. Ny "D" mengatakan kehamilan pada remaja membuat keluarga malu dan bisa saja remaja melakukan aborsi.

Hal ini sesuai dengan menurut Bakar, S.A (2014), masalah-masalah yang ditimbulkan akibat kehamilan pada remaja, antara lain:

a. Bagi remaja:

1) Sering terjadi keguguran atau aborsi.

2) Proses persalinan sering disertai kesulitan.

3) Kematian ibu.

4) Gangguan kejiwaan (misal: timbul rasa takut, tertekan yang dapat berlanjut keinginan bunuh diri).

5) Risiko putus sekolah.

b. Bagi bayi:

1) Bayi yang dilahirkan dengan BB rendah (BBLR).

2) Kematian bayi.

Siswi "I" mengatakan mengetahui tentang rokok, miras dan narkoba berbahaya untuk kesehatan karena dapat menyebabkan sakit jantung dan kanker hati. Siswa " $H$ " mengatakan dampak dari merokok, miras dan narkoba bisa membuat orang ketergantungan, menghabiskan uang dan merusak kesehatan. Ny "D" mengatakan banyak orang merokok meskipun telah mengetahui bahaya dari merokok itu sendiri seperti sakit paru-paru dan sakit jantung, miras dan narkoba dapat merusak pola pikir orang yang menggunakannya dan membuang-buang uang. Ny " $D$ " mengatakan sudah berulang kali meminta anaknya berhenti merokok tetapi tidak bisa apalagi ayahnya perokok juga.

Dr."M" mengatakan narkoba ataupun miras itu tidak baik untuk kesehatan reproduksi, itu akan merusak kesehatan reproduksi, dapat menghilangkan jati diri dan berbuat berbagai macam kejahatan. Kedua pertisipan hanya menjawab bahaya dari segi kesehatan umum bukan kesehatan reproduksi tidak sesuai dengan pernyataan menurut Dokter Sehat (2019), Rokok dan minuman beralkohol adalah dua hal yang sebaiknya dihindari oleh pria maupun wanita. Keduanya dapat memicu berbagai macam masalah kesehatan, termasuk kesehatan reproduksi. Kebiasan merokok dan minum alkohol pada wanita dikaitkan dengan gangguan ovulasi. Sedangkan pada pria, rokok dan alkohol dianggap dapat memengaruhi kualitas sperma.

Siswi "I" mengatakan sepengetahuannya PMS adalah penyakit yang dapat menular melalui hubungan seksual. Ny "H" mengatakan PMS adalah penyakit yang menular melalui hubungan seksual. Siswa "H" mengatakan PMS adalah penyakit yang ditularkan melalui hubungan seksual dan jarum suntik. Ny "D" mengatakan hanya pernah mendengar saja tanpa mengetahui apa itu penyakit menular seksual.

Dr. "M" mengatakan cara penularan HIV/AIDS terutama itu melalui hubungan seksual yang dilakukan dengan orang yang memiliki penyakit PMS, dan bisa dari tranfusi darah. Hal ini sesuai menurut Bakar,S.A (2014), ada 3 cara utama penularan PMS dan HIV/AIDS:

1. Hubungan seksual yang tidak terlindung, baik melalui vagina, anal, maupun oral (cara penularan utama lebih dari 90\%).

2. Penularan dari ibu ke janin selama kehamilan (HIV/AIDS, gonore, klamidia); sesudah bayi lahir (HIV/AIDS).

3. Melalui transfusi darah, suntikan atau kontak langsung dengan cairan darah atau produk darah (sifilis dan HIV/AIDS).

Siswi "I" mengatakan kekerasan seksual adalah kekerasan yang dilakukan saat berhubungan sex contohnya seperti pemerkosaan. Ny "H" mengatakan ia mengetahui kekerasan seksual itu seperti 
pemerkosaan dan pelecehan. Siswa " $H$ " mengatakan kekerasan seksual adalah melakukan kekerasan saat berhubungan seksual. Ny "D" mengatakan ia mengetahui kekerasan seksual itu seperti pemerkosaan.

Dr. "M" mengatakan kekerasan seksual adalah tidakan seksual yang dilakukan kepada anak-anak, orang-orang yang bukan istrinya, pada orang-orang yang melakukan perlawanan saat melakukan hubungan seksual sehingga menimbulkan trauma. Cara menghindarinya dengan memberikan pendidikan yang baik diberikan pengertian tentang kehidupan seksual yang baik dengan cara memberikan pendidikan seksual secara dini. Menurut Suyanto, Bagong (2018), untuk mengurangi resiko anak perempuan menjadi korban tindak kejahatan seksual, memang salah satu cara yang perlu dikembangkan adalah memberikan pendidikan seksual sejak dini kepada anakanak. Mengajarkan anak perempuan agar pandai-pandai menjaga tubuhnya, khususnya bagian intim tubuhnya sebagai sesuatu yang sakral dan tidak boleh sembarang disentuh orang lain, adalah pengetahuan dasar yang perlu ditransformasikan kepada anak-anak perempuan baik oleh orang tua maupun guru disekolah.

\section{KESIMPULAN}

Dari hasil penelitian didapatkan kesimpulan:

a. Perkembangan fisik, mental dan social kedua remaja partisipan berjalan dengan normal.

b. Kedua remaja partisipan menjaga dan merawat kesehatan reproduksinya belum maksimal, di karenakan kurangnya pengetahuan dan pemahaman participant tentang cara merawat kesehatan reproduksi yang benar.

c. Kedua remaja partisipan mengatahui dampak dari kehamilan remaja.

d. Kedua remaja partisipan mengatahui dan paham bahaya rokok, miras dan narkoba. e. Kedua remaja partisipan mengetahui yang di maksud dengan PMS.

f. Kedua remaja partisipan mengetahui dan paham pengertian dari kekerasan seksual.

\section{SARAN}

\section{Bagi Orang tua}

Diharapkan orang tua dapat memfasilitasi dalam memberikan pendidikan kesehatan reproduksi sedini mungkin pada anaknya, termasuk dengan menjaga kebersihan diri dan nutrisi anak dan remaja.

\section{Bagi Remaja}

Diharapkan para remaja dapat memahami dengan benar tentang kesehatan reproduksi dan dapat menghindari perilaku seksual yang berbahaya dengan menggali informasi dari berbagai sumber.

\section{Bagi Pihak Sekolah}

Perlunya kerjasama tim berupa koordinasi antara pihak sekolah dengan tenaga kesehatan dan program studi D III Kebidanan dalam melaksanakan KIE Kesehatan Reproduksi terpadu di sekolah yang terjadwal dan berkesinambungan.

\section{Bagi Peneliti Selanjutnya}

Diharapkan dapat melaksanakan penelitian yang lebih mendalam dan menemukan metode yang tepat untuk pelaksanaan KIE Kesehatan Reproduksi bagi remaja.

\section{UCAPAN TERIMA KASIH}

Penulis mengucapkan terima kasih kepada Ketua STIKES Mitra Adiguna Palembang yang telah memberi dukungan financial terhadap penelitian ini. 


\section{DAFTAR PUSTAKA}

Adwiyah. 2016. Hubungan Pengetahuan Ibu Hamil Terhadap Status Gizi pada Ibu Hamil di BPM Sri Handayani Palembang. Diakses Tanggal: 13 Maret 2019

Aqid, Z dan Ahmad Amrullah. 2017. Ensiklopedia Pendidikan Psikologi. Jakarta : Andi Offset

Bakar, S.A. 2014. Kesehatan Reproduksi dan Kelearga Berencana. Jakarta:PT Raja Grafindo Persada.

BN.2017. Prioritaskan Kesehatan Reproduksi Remaja untuk Menikmati Bonus Demografi. Diakses Tanggal : 10 Maret 2019

Dhafir. 2014. Pengetahuan Remaja Mengenai Kesehatan Reproduksi di SMAN 1 Dolo. Diakses Tanggal : 9 Maret 2019

https://doktersehat.com/cara-menjagakesehatan-organ-reproduksil. Diakses Tanggal : 25 mei 2019

Irawan, E. 2016. Gambaran Pengetahuan Remaja Tentang Kesehatan Reproduksi di Desa Kertajaya. Diakses Tanggal: 10 Maret 2019

Lilestiana, S. 2012. Pengaruh Pengetahuan tentang Kesehatan Reproduksi Remaja terhadap Perilaku Seksual Pranikah Remaja di Indonesia. Diakses Tanggal : 10 Maret 2019

Noviana, N. 2018. Kesehatan Reproduksi untuk Mahasiswa Kebidanan. Jakarta : CV. Trans Info Medika

Rohan, HH dan Sandu Siyanto. 2013. Buku Ajar Kesehatan Reproduksi. Yogyakarta: Nuha Medika

SDKI. 2012. Kesehatan Reproduksi Remaja. Diakses Tanggal : 10 Maret 2019
Suyanto, Bagong. 2018. Problem Pendidikan dan Anak Korban Tindak Kekerasan. Yogyakarta : Suluh Media 